\title{
OSCILLATION PROPERTIES OF HIGHER ORDER LINEAR IMPULSIVE DELAY DIFFERENTIAL EQUATIONS
}

\author{
KunWEn Wen And LiJun Pan
}

Abstract. In this paper, we devote to investigation of higher order impulsive delay differential equations. Some interesting results for oscillation properties of every bounded solution of equations are obtained. In addition, an example shows that impulses play an important role in the oscillation properties of the solutions.

Mathematics subject classification (2010): 34C10, 34C15. solutions.

Keywords and phrases: oscillation properties, impulsive differential equation, delay, linear, bounded

\section{REFERENCES}

[1] D.D. BAinov, M. Dimitrova, Oscillation of sub-and superlinear impulsive equations with constant delay, Appl. Anal., 64 (1997), 57-67.

[2] L. BereZANSKy, E. BRAVERMAn, Oscillation of a linear delay impulsive differential equations, Comm. Appl. Nonlinear Anal., 3 (1996), 61-67.

[3] L. BeREZANSK , E. BRAVERMAN, On oscillation of a second order impulsive linear delay differential equations, J. Math. Anal. Appl., 233 (1999), 276-300.

[4] W.Z. FENG, Y.S. CHEN, Oscillations of second order functional differential equations with impulses, Dym. Continuous, Discrete Impulsive System Ser. A:Math. Anal., 9 (2002), 367-376.

[5] K. Gopalsamy, B., Zhang, On delay differential equations with impulses, J. Math. Anal. Appl., 139 (1989), 110-122.

[6] G., HuAng, J.H. Shen, Oscillation of second-order linear ODE with impulses, J. Nat. Sci. Hunan Norm. Univ., 26 (2003), 8-10.

[7] V. Lakshmikantham, D. D. Bainov, P. S. Simeonov, Theory of Impulsive Differential Equations, World Scientific, Singapore, 1989.

[8] X.D. LI, Oscillation properties of higher order impulsive delay differential equations, International Journal of Difference Equations, 2, (2007), 209-219.

[9] L.J. PAN, G.Q. WANG, S.S. CHENG, Oscillations of even order nonlinear differential equations with impulses, Funk. Ekva., 50 (2007), 117-131.

[10] L.J. PAN, Oscillations of higher order nonlinear impulsive differential equations with damping, Appl. Math. J. Chinese Univ. Ser. A (in Chinese), 22, (2007), 35-42.

[11] K.W. WEN, G.Q. WANG, S.S. CHENG, Oscillations of a higher order nonlinear differential equations with impulses, Demonstratio Mathematica, 3 (2010), 575-603.

[12] K.W. Wen, G.Q. WAng, S.S. Cheng, Asymptotic dichotomy in a class of third-order nonlinear differential equations with Impulses, Abstract and Applied Analysis, ID: 562634, (2010), 1-20.

[13] K.W. WEN, L.J. PAN, Asymptotic dichotomy in a class of odd-order nonlinear differential equations with impulses, Journal of Industrial Mathematics, ID: 421231, (2013), 1-9.

[14] J.R. YAN, Oscillation of nonlinear delay impulsive differential equations and inequalities, J. Math. Anal. Appl., 265 (2002), 332-334.

[15] J.R. YAN, Oscillation propeties of second order impulsive delay differential equation, Comput. Math. Appl., 47 (2004), 253-258.

[16] Y. Zhang, A.M. ZhaO, J.R. YAn, Oscillatory criteria for impulsive delay differential equations, J. Math. Anal. Appl., 205 (1997), 461-470. 